TITLE: Application of thermogravimetric analysis to the evaluation of aminated solid sorbents for $\mathrm{CO}_{2}$ capture

AUTHORS: M.G. Plaza, C. Pevida, B. Arias, J. Fermoso, A. Arenillas, F. Rubiera*, J.J. Pis

ADDRESS: Instituto Nacional del Carbón, CSIC. Apartado 73. 33080 Oviedo, Spain

*Corresponding author: Dr. Fernando Rubiera

Instituto Nacional del Carbón, C.S.I.C.

Apartado 73

33080 Oviedo (Spain)

Telephone: +34 985118975

Fax: +34985297662

E-mail: frubiera@incar.csic.es

Number of pages: 10

Number of tables: 1

Number of figures: 6 


\title{
APPLICATION OF THERMOGRAVIMETRIC ANALYSIS TO THE EVALUATION OF AMINATED SOLID SORBENTS FOR $\mathrm{CO}_{2}$ CAPTURE
}

\author{
M.G. Plaza, C. Pevida, B. Arias, J. Fermoso, A. Arenillas, F. Rubiera, J.J. Pis \\ Instituto Nacional del Carbón, CSIC, Apartado 73, 33080 Oviedo, Spain
}

\begin{abstract}
In this work a series of solid sorbents were synthesized by immobilizing liquid amines on the surface of a mesoporous alumina. The samples were chemically characterized and BET surface areas calculated from the $\mathrm{N}_{2}$ adsorption isotherms at $77 \mathrm{~K}$. The $\mathrm{CO}_{2}$ capture performance of the sorbents and their thermal stability was studied by thermogravimetric methods. The effect of amine loading on the $\mathrm{CO}_{2}$ capture performance of the prepared sorbents was also evaluated. Analysis of TG-DTG curves showed that thermal stabilization of the amines is significantly improved by immobilizing them on an inorganic support. Temperature-programmed $\mathrm{CO}_{2}$ adsorption tests from $298 \mathrm{~K}$ up to $373 \mathrm{~K}$ at atmospheric pressure, proved to be a useful technique for assessing the capacity of sorbents for $\mathrm{CO}_{2}$ capture. Alumina impregnated with diethylentriamine presented the highest $\mathrm{CO}_{2}$ adsorption capacities throughout the tested temperature range.
\end{abstract}

Keywords: $\mathrm{CO}_{2}$ capture, thermogravimetric analysis, adsorption.

\section{Introduction}

Nowadays global warming is a major concern. The observed increase in average temperatures since the mid-20 ${ }^{\text {th }}$ century is very likely due to the increase in anthropogenic greenhouse gas (GHG) concentrations, with carbon dioxide being the most important contributor. Moreover, annual fossil carbon dioxide emissions increased from an average of $6.4 \mathrm{GtC}$ per year in the 1990 s to $7.2 \mathrm{GtC}$ per year in the period 2000-2005 [1]. The UN Framework Convention on Climate Change, ratified by 186 countries, calls for the stabilization of GHGs, which implies deep reductions in global emissions. Although eventually a new energy scenario must be developed in pro of sustainability, in the short to medium term $\mathrm{CO}_{2}$ capture and storage (CCS) from large stationary sources, such as power generation plants (post-combustion capture), is a feasible method for cutting down emissions. CCS involves separating $\mathrm{CO}_{2}$ from other 
gases, by compressing and transporting it to an adequate storage site. At present, the preferred technology for post-combustion capture is amine scrubbing. However, its high energy requirements result in a significant efficiency penalty on the power cycle. Adsorption on porous solids is an emerging alternative that seeks to reduce the costs associated to the capture step.

Porous solids are extensively used for the removal of gaseous contaminants in air, and Pressure Swing Adsorption (PSA) is already the system of choice for the removal of $\mathrm{CO}_{2}$ from syngas for hydrogen production. The main drawback of adsorption processes in post-combustion $\mathrm{CO}_{2}$ capture is the necessity of cooling and drying the flue gas. The development of a new generation of materials that would efficiently adsorb $\mathrm{CO}_{2}$ at moderate temperatures, will undoubtedly enhance the competitiveness of adsorption separation in flue gas applications [2]. Basic alumina can be used directly as an adsorbent for the removal and recovery of $\mathrm{CO}_{2}$ from power plant flue gases, due to its high resistance to steam and good mechanical and thermal stability properties [3]. However, it would be desirable to improve its capacity for adsorbing $\mathrm{CO}_{2}$, especially above room temperature. The enhancement of a specific adsorption capacity may be carried out by promoting chemisorption through impregnation with chemicals that react reversibly with $\mathrm{CO}_{2}$, such as amines. There have been a number of studies on the immobilization of amines for different purposes [4-15]. In this work several compounds were evaluated as potential sources of amine groups for producing high efficiency $\mathrm{CO}_{2}$ sorbents.

Apart from being energy intensive, one of the main drawbacks of amine scrubbing is the solvent losses associated to the high volatility of amines. Thus, one of the objectives of this work was to study the influence of the support on the thermal stability of amines. However, the main aim was to study the capture performance of the sorbents under different conditions, in order to select the suitable impregnate and operating temperature for the adsorption process. The standardized methods used in sorption measurements are gravimetric and volumetric ones [16]. However, these methods are very time consuming. Simple and short experiments in a thermobalance allow rational decisions to be made in a preliminary screening where multiple variables are being considered. In just one experiment, the capacity of an adsorbent can be evaluated over an entire temperature range; likewise, qualitative information about the initial adsorption rates can be obtained. Thermogravimetry, which has been previously applied to the 
preparation and characterization of adsorbents [17-21], has also proved to be a useful technique for preliminary adsorption capacity assessment.

\section{Experimental}

A commercial activated alumina, here referred to as A, was selected as the starting material. This partially hydroxylated aluminium oxide has a pore system consisting mainly of meso and macropores, which has proved to be highly suitable for impregnation purposes. The textural characterization of A showed a mesoporous volume of $0.327 \mathrm{~mL} \mathrm{~g}^{-1}$ calculated by the density functional theory (DFT) method from the $\mathrm{N}_{2}$ adsorption isotherm at $77 \mathrm{~K}$ [22].

A series of sorbents were obtained by loading A with the following compounds: diethylentriamine (DETA), diisopropanolamine (DIPA), triethanolamine (TEA), 2-amino-2-methyl-1,3-propanediol (AMPD), pentaethylenehexamine (PEHA), and polyethylenimine (PEI). These compounds were selected due to their different composition and structure: DIPA is a commercially used alkanolamine, AMPD a sterically hindered alkanolamine and TEA is a tertiary alkanolamine. DETA, PEHA and PEI are alkylamines that present a mixture of primary and secondary amine groups and differ mostly in their molecular mass. The amines were immobilized through a wet impregnation method adapted from $\mathrm{Xu}$ et al. [23]. The impregnated samples were denoted as A-X, where X represents the type of amine loaded. For series A-X the initial amount of amine was always $40 \%$ mass/mass with respect to the support.

The samples obtained were characterized in terms of elemental composition, surface chemistry, texture, thermal stability and $\mathrm{CO}_{2}$ capture performance.

\subsection{Chemical characterization}

The prepared sorbents were subjected to proximate and ultimate analyses to quantify the degree of impregnation achieved from the increase in volatile matter and nitrogen content. In order to study the influence of impregnation on the acid-base properties of the carbon surfaces, the point of zero charge $\left(\mathrm{pH}_{\mathrm{PZC}}\right)$ was estimated by a mass titration method adapted from Noh and Schwarz [24].

\subsection{Textural characterization}

Textural characterization of the prepared sorbents was carried out by $\mathrm{N}_{2}$ adsorption isotherms at $77 \mathrm{~K}$ in a Micromeritics TriStar 3000. Prior to the measurements the 
samples were outgassed at room temperature under vacuum for $24 \mathrm{~h}$. The apparent surface area was evaluated from the $\mathrm{N}_{2}$ adsorption isotherm by the BET equation in the linear form proposed by Parra et al. [25].

\subsection{Thermogravimetric study}

Thermal stability tests were carried out in a thermogravimetric analyzer Setaram TGA 92 coupled to a Nicolet Nexus FTIR analyzer through a TGA interface. The gas line was heated to prevent condensation of the evolved gases. These experiments involved heating the sample at a rate of $15 \mathrm{~K} \mathrm{~min}^{-1}$ up to $1273 \mathrm{~K}$ under a flow rate of $50 \mathrm{~mL} \mathrm{~min}^{-1}$ of Ar. Thermogravimetric analysis combined with FTIR spectroscopy provides information regarding mass changes in a sample and allows the qualitative identification of the gases evolved during thermal degradation [26].

\section{4. $\mathrm{CO}_{2}$ sorption measurements}

The $\mathrm{CO}_{2}$ adsorption and desorption performance of the sorbents was also evaluated by thermogravimetric analysis. The $\mathrm{CO}_{2}$ capture capacity of the sorbents was determined by measuring the mass uptake of the sample when exposed to pure $\mathrm{CO}_{2}$. Capacity was expressed as mass percentage of dry sorbent. Typically, one sphere of alumina (ca. $200 \mathrm{mg}$ ) was placed in a platinum crucible and suspended in the thermobalance. Prior to the adsorption measurements, the sample was dried at $373 \mathrm{~K}$ in $50 \mathrm{~mL} \mathrm{~min}^{-1}$ of Ar for $1 \mathrm{~h}$, and then allowed to cool to $298 \mathrm{~K}$. The flow was then changed to $50 \mathrm{~mL} \mathrm{~min}^{-1}$ of pure $\mathrm{CO}_{2}$ and the temperature was maintained at $298 \mathrm{~K}$ for $6 \mathrm{~h}$. The mass uptake during this stage was interpreted as the $\mathrm{CO}_{2}$ capture capacity of the sample at $298 \mathrm{~K}$. Afterwards, the temperature was increased at a rate of $0.2 \mathrm{~K} \mathrm{~min}^{-1}$ up to $373 \mathrm{~K}$ and the mass change was recorded to evaluate the influence of temperature upon the $\mathrm{CO}_{2}$ adsorption capacity of the sample. Finally, the sample was kept at $373 \mathrm{~K}$ and then the flow was changed again to Ar to regenerate the sample.

\section{Results and discussion}

From the chemical analysis of the samples, shown in Table 1, it can be seen that impregnation greatly increased the nitrogen and carbon contents of the samples due to the contribution of the immobilized amines. The results also evidence the effectiveness of the impregnation method performed. The oxygen content of the samples impregnated with the alkanolamines (A-DIPA, A-AMPD, A-TEA) doubled that of the ones 
impregnated with alkylamines (A-DETA, A-PEHA, A-PEI), due to the presence of hydroxyl groups in the structure of the amines. The volatile matter (ca. 8 mass \%, db) of the alumina support, $\mathrm{A}$, is assigned to chemically combined water, as will be discussed below. In the case of the impregnated samples, A-X, the higher volatile matter content is due to the incorporation of the different types of amines.

The changes in $\mathrm{pH}_{\mathrm{PzC}}$ reflect variations in the ratio between the acidic and basic surface groups of the samples. The estimated value of $\mathrm{pH}_{\mathrm{PZC}}$ for $\mathrm{A}$ (see Table 1) is in good accordance with the values found in the literature [24, 27]. Impregnation caused a slight shift in the $\mathrm{pH}_{\mathrm{PZC}}$ of the sorbents towards higher values due to the immobilization of basic amine groups. The basic nature of the sorbents is expected to be favourable for their application in the adsorption of an acidic gas, such as $\mathrm{CO}_{2}$.

However, impregnation had a negative effect on the texture of the resultant sorbents, as shown by the significant decrease in the BET surface areas presented in Table 1 . This decrease is a consequence of pore blockage by the amine film.

Temperature-programmed desorption (TPD) tests were carried out on the prepared sorbents, and also on the initial amines, to check their thermal stability. Free amines decomposed in a single step below $673 \mathrm{~K}$ (see Figure 1a), DETA being the least stable of the tested amines and PEI the thermally most stable. The DTG curves for the support, A, and the impregnated samples are presented in Figure 1b. The alumina support, A, showed a continuous mass loss between 373 and $1273 \mathrm{~K}$ with a maximum at $873 \mathrm{~K}$. This is attributed to the evolution of physically adsorbed water at low temperatures, while at temperatures above $473 \mathrm{~K}$ it is ascribed to chemically combined water that comes from the hydroxylated nature of the aluminum oxide. For the impregnated samples the DTG curves present two main peaks followed by a shoulder around $873 \mathrm{~K}$ attributed to the alumina support. The first peaks appeared above $473 \mathrm{~K}$ and are mostly ascribed to methanol evolution, as this is the solvent used in the wet impregnation procedure. The second peaks (ca. $773 \mathrm{~K}$ ) correspond to $\mathrm{NH}_{3}$ evolved from the decomposition of the immobilized amine groups. In addition, the higher decomposition temperatures of the supported amines compared to those of the initial liquid amines revealed that the amine groups were effectively stabilized on the alumina support by interaction forces between the amine film and the solid support.

The $\mathrm{CO}_{2}$ adsorption and desorption potential of the prepared adsorbents was assessed using a thermogravimetric analyzer. Figure 2 displays the $\mathrm{CO}_{2}$ capture capacities of the studied samples against temperature during the non-isothermal stage between $298 \mathrm{~K}$ and 
$373 \mathrm{~K}$. The alumina support, A, and the alkanolamine-impregnated samples (A-TEA, A-AMPD and A-DIPA) showed a decrease in $\mathrm{CO}_{2}$ adsorption with increasing temperature while the alkylamine-impregnated samples (A-DETA, A-PEHA, and A-PEI) presented an increase in $\mathrm{CO}_{2}$ capture capacity from $298 \mathrm{~K}$ to $373 \mathrm{~K}$. For the raw support, $\mathrm{A}, \mathrm{CO}_{2}$ capture could only be due to physisorption occurring within its pore structure. However, the impregnated samples include amine type functionalities that may also contribute to the overall capture capacity. Due to the absence of water in the system, the only possible reaction between amines and $\mathrm{CO}_{2}$ would be the formation of carbamates:

$$
\mathrm{R}_{2} \mathrm{NH}+\mathrm{CO}_{2} \stackrel{\text { low temperature }}{\underset{\text { heat }}{\rightleftharpoons}} \mathrm{R}_{2} \mathrm{NCOO}^{-}+\mathrm{R}_{2} \mathrm{NH}_{2}^{+}
$$

Carbamates can be formed only by primary and secondary amines but not by tertiary amines, such as TEA [28, 29]. Hence $\mathrm{CO}_{2}$ adsorption on A-TEA occurs only by physisorption, showing a similar behaviour to that of the alumina support, A, although with a lower overall capacity due to the lower surface area of A-TEA (i.e., $58 \mathrm{~m}^{2} / \mathrm{g}$ vs $271 \mathrm{~m}^{2} / \mathrm{g}$ for A-TEA and A, respectively). A-AMPD also exhibited a poor performance towards $\mathrm{CO}_{2}$ capture $-\mathrm{CO}_{2}$ capture capacities lower than A-. This is most probably due to steric hindrance, as AMPD is by structural definition a sterically hindered amine, with a primary amine group attached to a tertiary carbon [30]. Therefore, for A-AMPD, $\mathrm{CO}_{2}$ adsorption would proceed again mainly through physisorption in the pores. The alkylamine-impregnated samples (A-DETA, A-PEHA and A-PEI) and A-DIPA presented better performance for $\mathrm{CO}_{2}$ capture than the alumina support, demonstrating the favourable contribution of the surface chemistry introduced by the amine immobilization.

As carbamate formation is an exothermic reaction, it might be expected that an increase in temperature would reduce the capture capacity of the impregnated samples as happens with A-DIPA. However, the contrary was observed for A-DETA, A-PEHA and A-PEI. In an analysis of the structure of these three impregnates it was found that the common factor between them is the presence of more than one amino group (primary and secondary amines) in their structure. Therefore, a possible explanation for this behaviour could be an improvement of $\mathrm{CO}_{2}$ diffusivity through the amine film with temperature, as this would allow more amine groups to react, as previously suggested by other authors [31]. Mass transfer would be the rate limiting step for $\mathrm{CO}_{2}$ capture in these samples, leading to a linear behaviour of $\mathrm{CO}_{2}$ capacity with respect to 
temperature, as diffusivity is directly proportional to temperature. In fact, from $323 \mathrm{~K}$ A-DETA, A-PEHA and A-PEI showed an increase in $\mathrm{CO}_{2}$ uptake with nearly the same slope, suggesting that this behaviour is not influenced by the type of impregnate.

Of all the prepared adsorbents A-DETA showed the highest capture capacity over the entire temperature range studied. The possibility of capturing $\mathrm{CO}_{2}$ at temperatures such as $373 \mathrm{~K}$ would be an attractive advantage for the subsequent application of these sorbents, as this would reduce the need to cool the flue gases in the post combustion capture systems installed in power stations.

The effect of amine loading was also studied by preparing a series of samples impregnated with DETA. The samples were denoted as A-DETA3, A-DETA7 and A-DETA12 where the number represents their nitrogen content after impregnation (dry basis). Figure 3 shows the $\mathrm{N}_{2}$ adsorption isotherms of the as-prepared samples. It can be observed that a higher amine loading reduces the textural properties of the support significantly, as the amine film partially or totally fills the pore system depending on the load of amine used. A-DETA12 exhibits the maximum loading as almost all the pore system of the support is completely filled or blocked by DETA.

Thermal stability tests were also carried out for the A-DETA series, and the evolved gases were analyzed by FTIR. Figure 4 presents the DTG curves and the resulting profiles of the evolved $\mathrm{NH}_{3}$. As the loading increases, so does the rate of mass loss. The DTG curves present two characteristic decomposition intervals: a sharp peak ca. $473 \mathrm{~K}$ and a softer band at around 673-773 K. The first DTG peak can be mainly assigned to water and methanol, while the latter represents mostly ammonia and ethane, from the decomposition of DETA. The evolution of $\mathrm{NH}_{3}$ starts at $573 \mathrm{~K}$ and reaches a maximum at around $673 \mathrm{~K}$. The aim of impregnation is to immobilize the amine on the support. However, during this process, water and methanol are thought to be trapped by the amine film in the porous system of the alumina, their contribution to mass loss being more significant for higher loadings of amine, as shown by the greater area below the first DTG peak. Thus, to evaluate the yield of the impregnation (i.e., amount of immobilized amine per total loading) the $\mathrm{NH}_{3}$ intensities were corrected in accordance with the amount of mass loss during the TPD tests (40 mg for A-DETA3, $65 \mathrm{mg}$ for A-DETA7 and $123 \mathrm{mg}$ for A-DETA12). As previously mentioned, this mass loss corresponds not only to the immobilized amine but also to other volatiles, fundamentally water and methanol. A-DETA3 showed the highest $\mathrm{NH}_{3}$ intensity per milligram of mass loss, suggesting that it was the most effective load. 
The capture tests carried out on the A-DETA series (Figure 5) showed that the $\mathrm{CO}_{2}$ capture capacity of the raw support at $298 \mathrm{~K}$ was doubled by impregnation with different amounts of DETA. However, it was also observed that increasing impregnation loadings slow down the initial adsorption rate, due to resistance to mass transfer through the amine film. While A reaches its maximum capture capacity in only 17 min, A-DETA3 and A-DETA7 require 60 min, and A-DETA12 takes ca. $200 \mathrm{~min}$.

Figure 6 displays the influence of temperature on the $\mathrm{CO}_{2}$ capture capacity of the A-DETA samples. Lower loadings (A-DETA3) resulted in a sorption rate-controlled process where an increase in temperature diminished $\mathrm{CO}_{2}$ capture capacity. As DETA load was increased, a gradual change in the rate-limiting step was observed. For A-DETA7 a stable $\mathrm{CO}_{2}$ uptake was observed up to $343 \mathrm{~K}$, while for the highest loading (A-DETA12), mass transfer seems to be the limiting step up to $363 \mathrm{~K}$ as shown by the promoting effect of temperature on capacity.

\section{Conclusions}

Six different amines were successfully immobilized on an alumina support through a wet impregnation method, resulting in improved thermal stability compared to that of the initial liquid amines. Furthermore, the results showed the potential of impregnating alumina with amines for $\mathrm{CO}_{2}$ capture purposes. The sample impregnated with DETA presented the highest $\mathrm{CO}_{2}$ capture capacity throughout the studied temperature range (298-373 K). A-DETA doubled the $\mathrm{CO}_{2}$ capture capacity of the raw alumina at $298 \mathrm{~K}$ (i.e. 6 mass \% vs 3 mass \%). Moreover, A-DETA presented ca. 8 mass \% $\mathrm{CO}_{2}$ uptake at $373 \mathrm{~K}$, whilst the raw alumina only achieved 1 mass \% of $\mathrm{CO}_{2}$ capture at the same temperature. The high $\mathrm{CO}_{2}$ capacities achieved by the adsorbents at $373 \mathrm{~K}$, and the important consequences of using them for $\mathrm{CO}_{2}$ capture in flue gases must also be pointed out.

$\mathrm{CO}_{2}$ adsorption on amine-impregnated alumina cannot be explained by a single process, as it can be controlled by physical/chemical sorption or by mass transfer. Therefore, the type and load of amine used to impregnate the support and the temperature of the process need to be optimized. Moreover, to produce an effective $\mathrm{CO}_{2}$ solid sorbent a compromise between maximum capture capacity at the desired temperature and the kinetics of $\mathrm{CO}_{2}$ adsorption (i.e., $\mathrm{CO}_{2}$ capture rate) may be required. 


\section{Acknowledgements}

This work was carried out with financial support from the Spanish MEC (Project CTM2005-03075/TECNO). M.G.P. and C.P. acknowledge the support received from the CSIC I3P Program co-financed by the European Social Fund.

\section{References}

[1] Climate Change 2007: The Physical Science Basis. IPCC, 2007. http://www.ipcc.ch/SPM2feb07.pdf.

[2] IPCC Special Report on Carbon Dioxide Capture and Storage. Cambridge University Press, 2005.

[3] Z. Yong, V. G. Mata, A. R. E. Rodrigues, Adsorption, 7 (2001) 41.

[4] T. Hayashi, M. Kumita, Y. Otani, Environ. Sci. Technol., 39 (2005) 5436.

[5] H. Kasaini, Sep. Sci. Technol., 36 (2001) 2845.

[6] J. A. C. Alves, C. Freire, B. de Castro, J. L. Figueiredo, Colloids and Surfaces A: Physicochem. Eng. Aspects, 189 (2001) 75.

[7] D. A. Buttry, J. C. M. Peng, J.-B. Donnet, S. Rebouillat, Carbon, 37 (1999) 1929.

[8] W. Yantasee, Y. Lin, K. L. Alford, B. J. Busche, G. E. Fryxell, M. H. Engelhard, Sep. Sci. Technol., 39 (2004) 3263.

[9] X. Xu, C. Song, B. G. Miller, A. W. Scaroni, Fuel Process. Technol., 86 (2005) 1457.

[10] M. L. Gray, Y. Soong, K. J. Champagne, H. Pennline, J. P. Baltrus, R. W. Stevens Jr., R. Khatri, S. S. C. Chuang and T. Filburn, Fuel Process. Technol., 86 (2005) 1449.

[11] G. P. Knowles, S. W. Delaney, A. L. Chaffee, Ind. Eng. Chem. Res., 45 (2006) 2626.

[12] A. Arenillas, K. M. Smith, T. C. Drage, C. E. Snape, Fuel, 84 (2005) 2204.

[13] P. J. Birbara, T. A. Nalette. Regenerable supported amine-polyol sorbent, 1994. United Technologies Corporation, United States.

[14] S. Satyapal, T. Filburn, J. Trela, J. Strange, Energy \& Fuels, 15 (2001) 250.

[15] M. M. Maroto-Valer, Z. Tang, Y. Zhang, Fuel Process. Technol., 86 (2005) 1487.

[16] J. U. Keller, E. Robens, J. Thermal Anal. Calorimetry, 71 (2003) 37.

[17] T. Lupascu, I. Dranca, V. T. Popa, M. Vass, J. Thermal Anal. Calorimetry, 63 (2001) 855.

[18] K. Chrissafis, K. M. Paraskevopoulos, J. Thermal Anal. Calorimetry, 81 (2005) 463.

[19] V. L. Budarin, J. H. Clark, A. A. Gorlova, N. A. Boldyreva, V. K. Yatsimirsky, J. Thermal Anal. Calorimetry, 62 (2000) 349.

[20] L. Wachowski, M. Hofman, J. Thermal Anal. Calorimetry, 83 (2006) 379.

[21] M. M. G. R. Vianna, J. Dweck, V. F. J. Kozievitch, F. R. Valenzuela-Diaz, P. M. Buchler, J. Thermal Anal. Calorimetry, 82 (2005) 595.

[22] N. A. Seaton, J. P. R. B. Walton, N. Quirke, Carbon, 27 (1989) 853.

[23] X. Xu, C. Song, J. M. Andresen, B. G. Miller, A. W. Scaroni, Microporous Mesoporous Mater., 62 (2003) 29.

[24] J. S. Noh, J. A. Schwarz, J. Colloid Interface Sci., 130 (1988) 157.

[25] J. B. Parra, J. C. de Sousa, R. C. Bansal, J. J. Pis, J. A. Pajares, Adsorption Sci. Technol., 12 (1995) 51. 
[26] I. Pitkanen, J. Huttunen, H. Halttunen, R. Vesterinen, J.Thermal Anal. Calorimetry, 56 (1999) 1253.

[27] J. P. Reymond, F. Kolenda, Powder Technol., 103 (1999) 30.

[28] T. L. Donaldson, Y. N. Nguyen, Ind. Eng. Chem. Fund., 19 (1980) 260.

[29] E. F. da Silva, H. F. Svendsen. Chemistry of solvents for $\mathrm{CO}_{2}$ capture. In: $8^{\text {th }}$ International Conference on Greenhouse Gas Control Technologies. Trondheim 2006.

[30] G. Sartori, D. W. Savage, Ind. Eng. Chem. Fund., 22 (1983) 239.

[31] X. Xu, C. Song, J. M. Andresen, B. G. Miller, A. W. Scaroni, Energy \& Fuels, 16 (2002) 1463. 


\section{List of Tables}

Table 1. Chemical composition, point of zero charge ( $\mathrm{pH}_{\mathrm{PZC}}$ ) and BET surface area of the samples 


\section{List of Figures}

Figure 1. Thermal stability of the amines studied: a) as-received, b) immobilized on the alumina support.

Figure 2. Effect of temperature on the $\mathrm{CO}_{2}$ capture capacity of the commercial alumina, A, and the immobilized amines.

Figure $3 . \mathrm{N}_{2}$ adsorption isotherms measured at $77 \mathrm{~K}$ for the A-DETA series.

Figure 4. Thermal stability tests for the A-DETA series: a) DTG profiles b) $\mathrm{NH}_{3}$ emission analyzed by FTIR.

Figure 5. Influence of amine loading on the $\mathrm{CO}_{2}$ sorption rate of the A-DETA series at 298 K.

Figure 6. Effect of temperature on the $\mathrm{CO}_{2}$ capture capacity of the A-DETA series. 
Table 1. Chemical composition, point of zero charge ( $\left.\mathrm{pH}_{\mathrm{PZC}}\right)$ and BET surface area of the samples

\begin{tabular}{|c|c|c|c|c|c|c|c|c|c|}
\hline \multirow{2}{*}{ Sample } & \multicolumn{3}{|c|}{$\begin{array}{l}\text { Proximate analysis } \\
\text { (mass \%) }\end{array}$} & \multicolumn{4}{|c|}{$\begin{array}{l}\text { Ultimate analysis } \\
\text { (mass \%, db) }\end{array}$} & \multirow{2}{*}{$\mathrm{pH}_{\mathrm{PZC}}$} & \multirow{2}{*}{$\begin{array}{l}\mathrm{S}_{\mathrm{BET}} \\
\left(\mathrm{m}^{2} \mathrm{~g}^{-1}\right)\end{array}$} \\
\hline & Moisture & $\begin{array}{l}\text { Ash } \\
\text { (db) }\end{array}$ & $\begin{array}{l}\mathrm{VM} \\
(\mathrm{db})\end{array}$ & $\mathrm{C}$ & $\mathrm{H}$ & $\mathrm{N}$ & $\mathrm{O}^{\mathrm{a}}$ & & \\
\hline A & 7.5 & 83.4 & 7.8 & 0.3 & 1.2 & 0.0 & 15.1 & 9.1 & 271 \\
\hline A-DETA & 5.1 & 80.6 & 19.5 & 7.8 & 2.6 & 6.7 & 2.3 & 10.2 & 60 \\
\hline A-DIPA & 3.3 & 72.1 & 29.4 & 12.5 & 3.5 & 2.4 & 9.5 & 10.5 & 37 \\
\hline A-AMPD & 2.4 & 82.9 & 17.1 & 5.5 & 2.0 & 1.5 & 8.1 & 10.2 & 149 \\
\hline A-TEA & 2.5 & 73.3 & 28.4 & 11.1 & 2.9 & 2.1 & 10.6 & 9.6 & 58 \\
\hline A-PEHA & 2.2 & 70.0 & 32.2 & 13.4 & 3.7 & 8.5 & 4.4 & 11.1 & 24 \\
\hline A-PEI & 4.7 & 74.3 & 27.5 & 11.5 & 3.2 & 6.8 & 4.2 & 11.0 & 58 \\
\hline
\end{tabular}

${ }^{a}$ calculated by difference

db: dry basis 
Figure 1
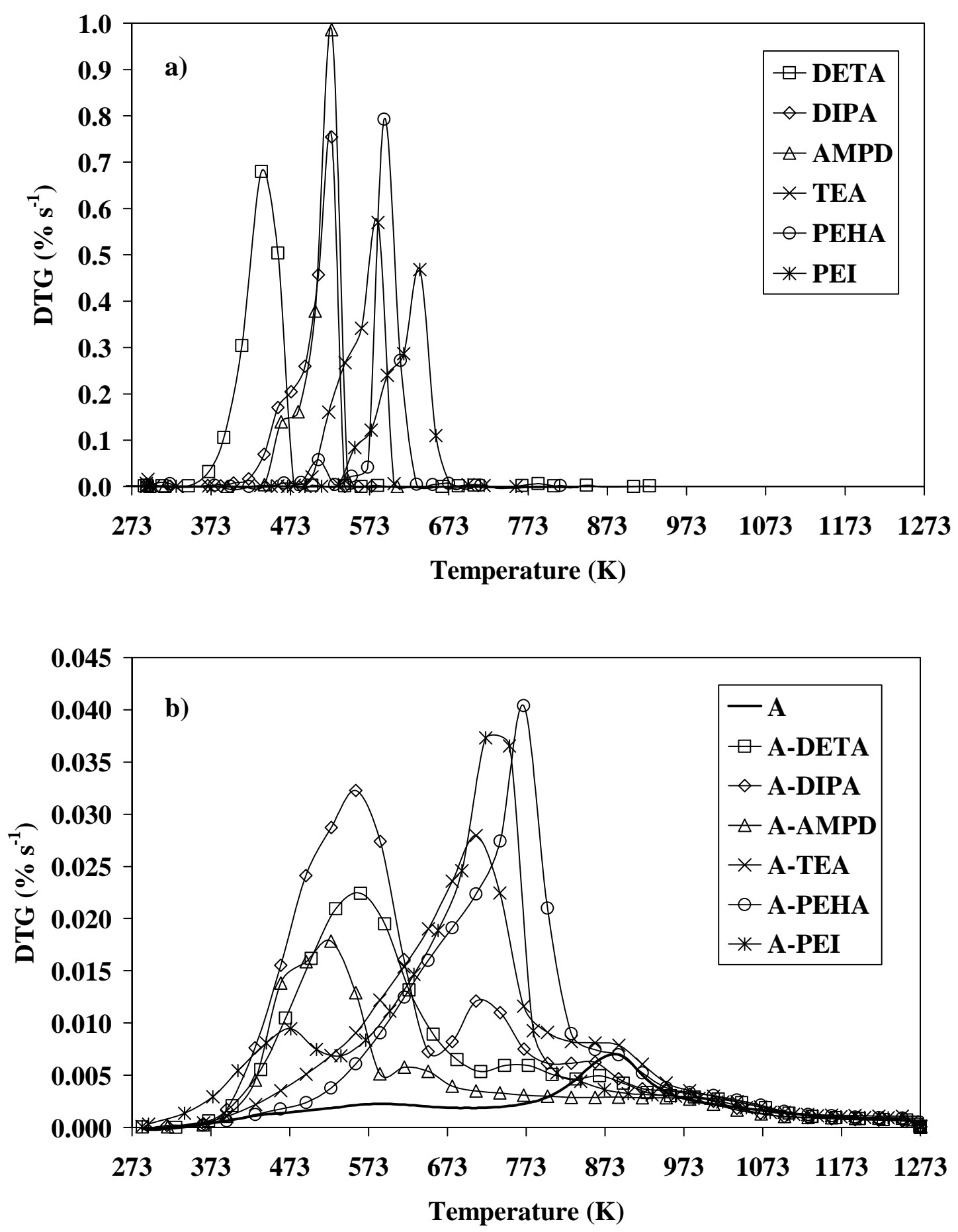

aza et al., J. Thermal Anal. Calorimetry 
Figure 2

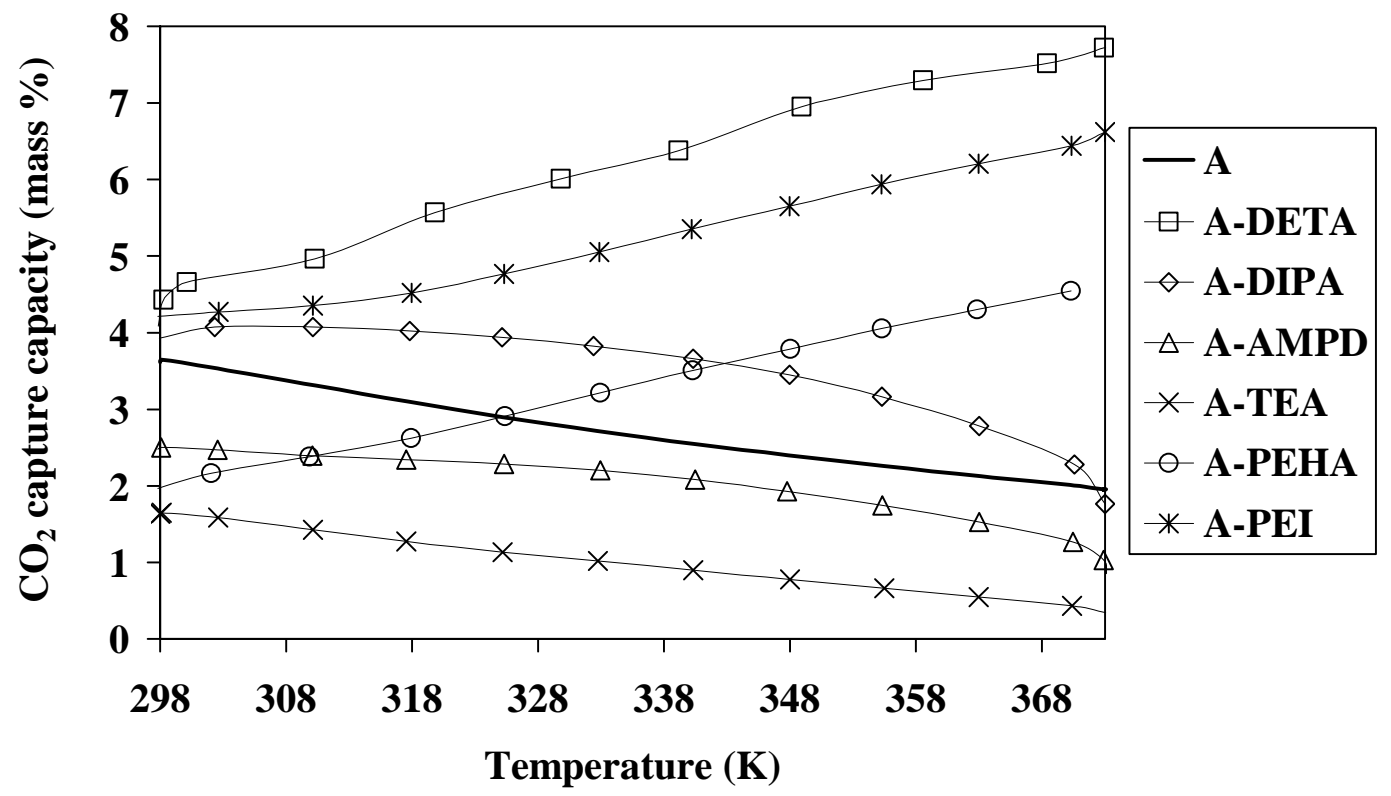


Figure 3

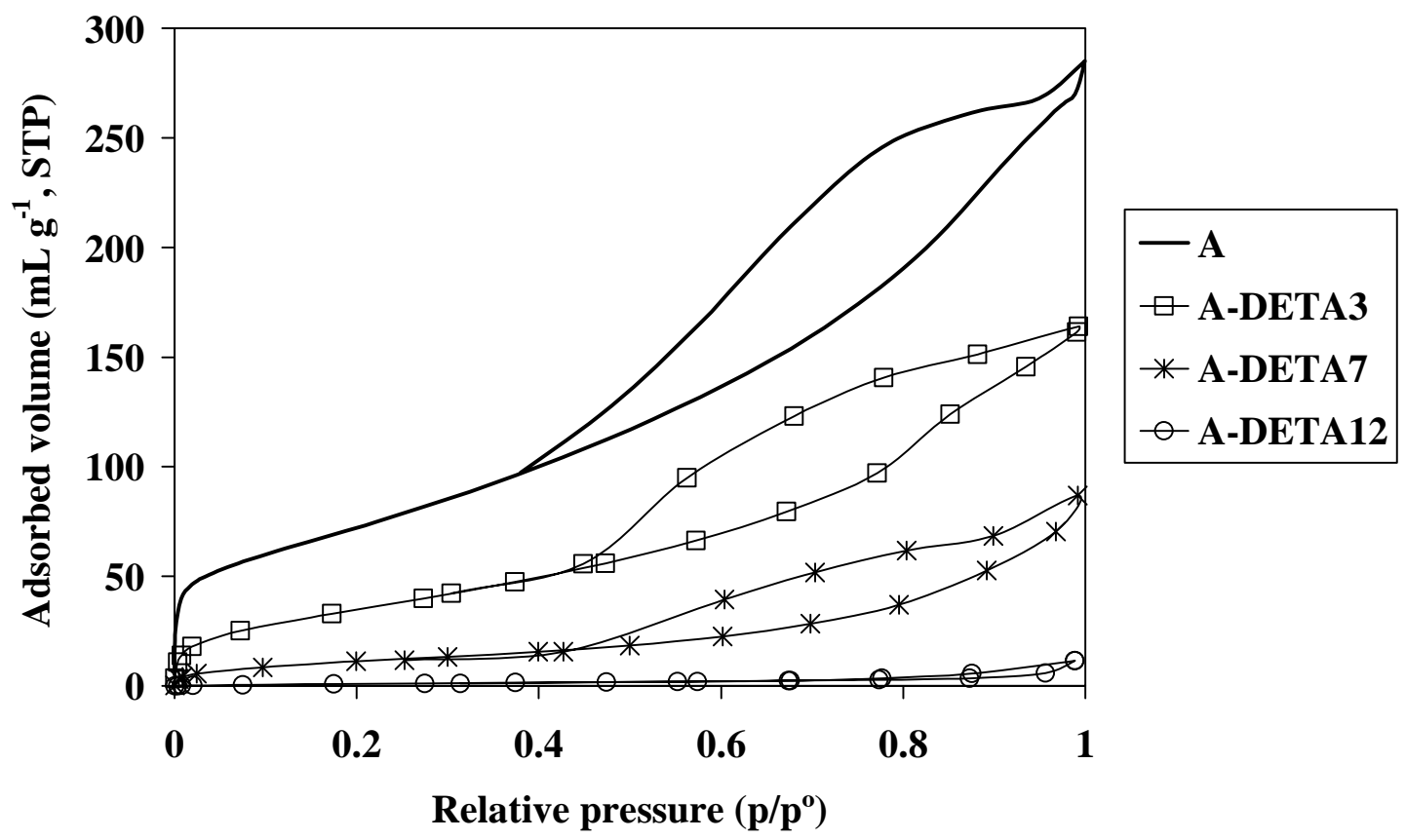


Figure 4
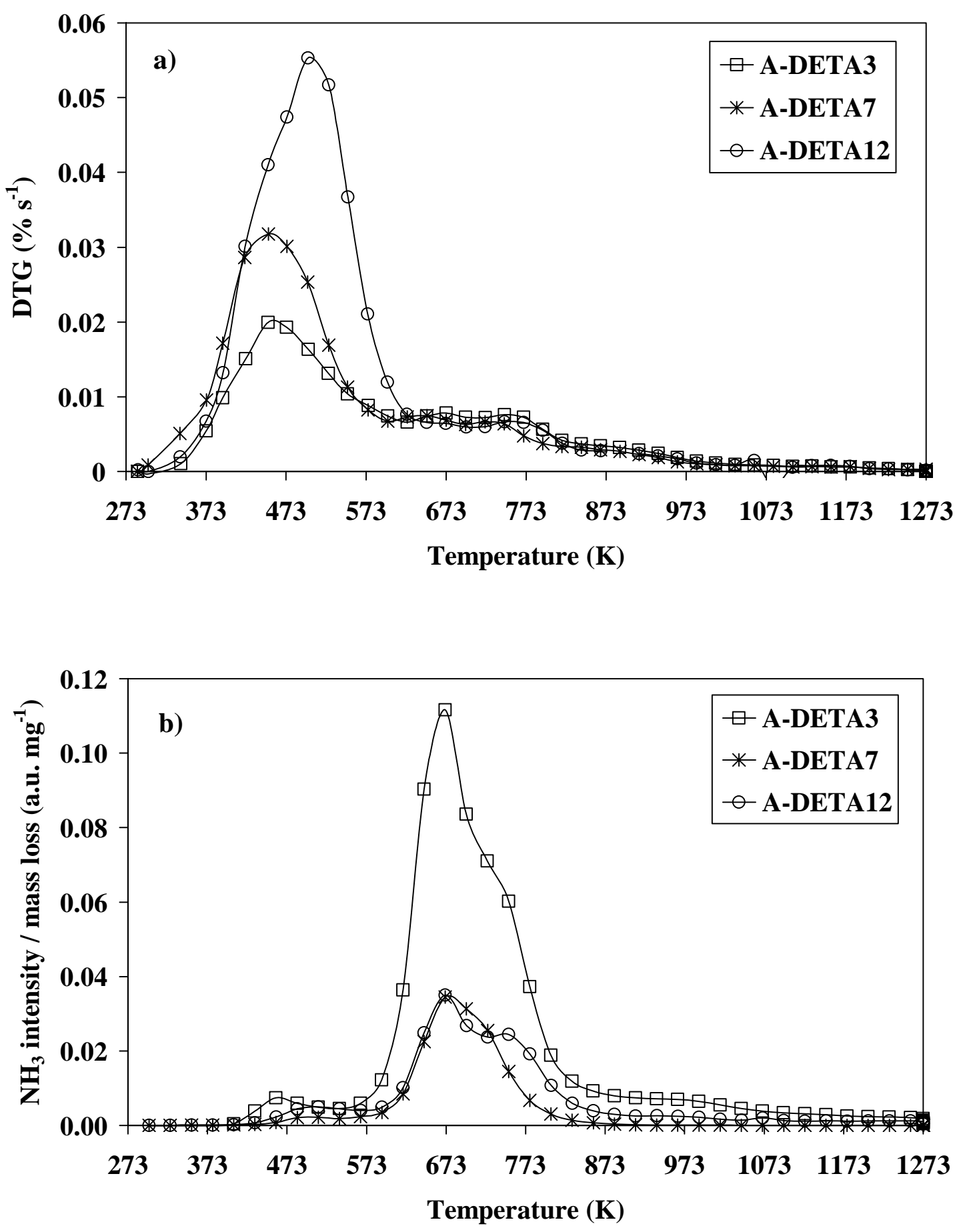
Figure 5

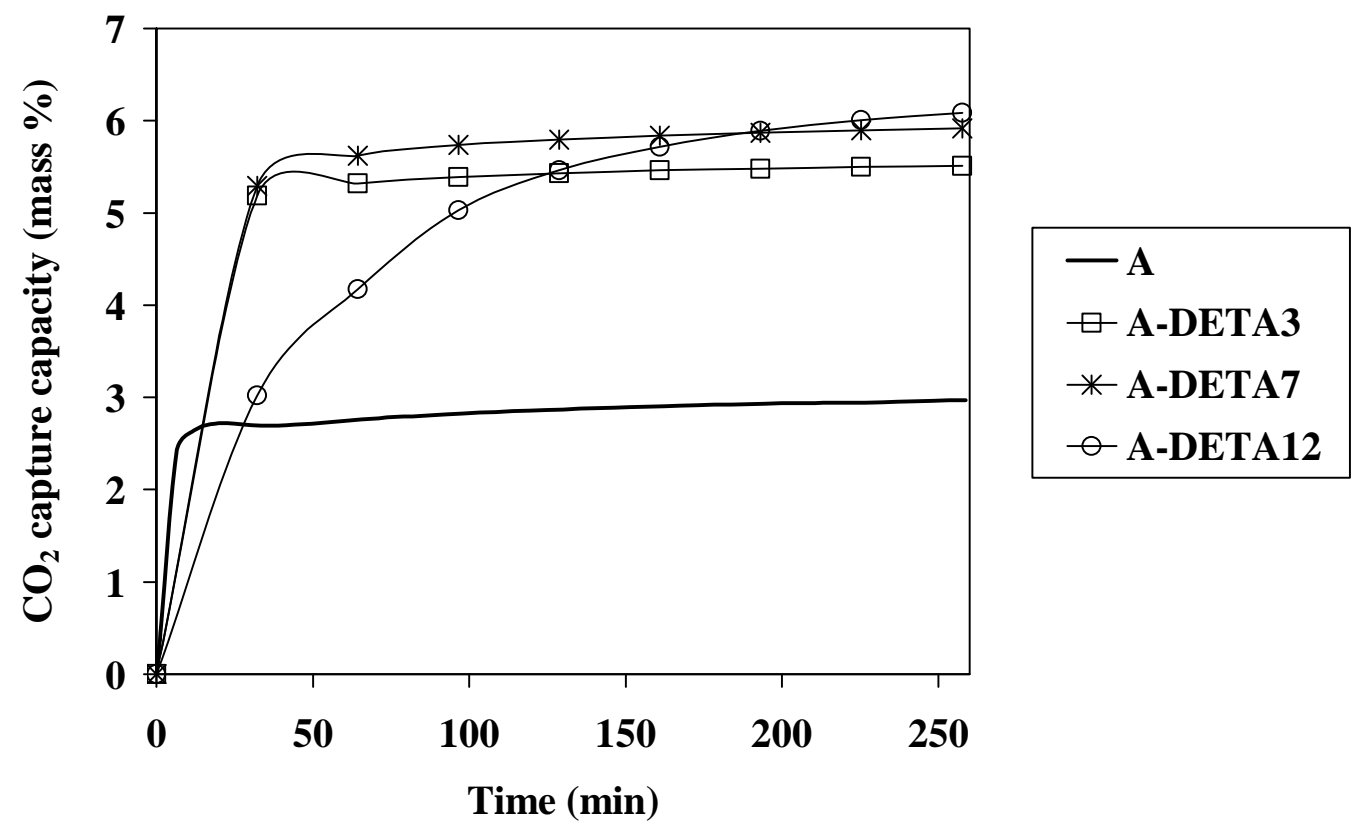


Figure 6

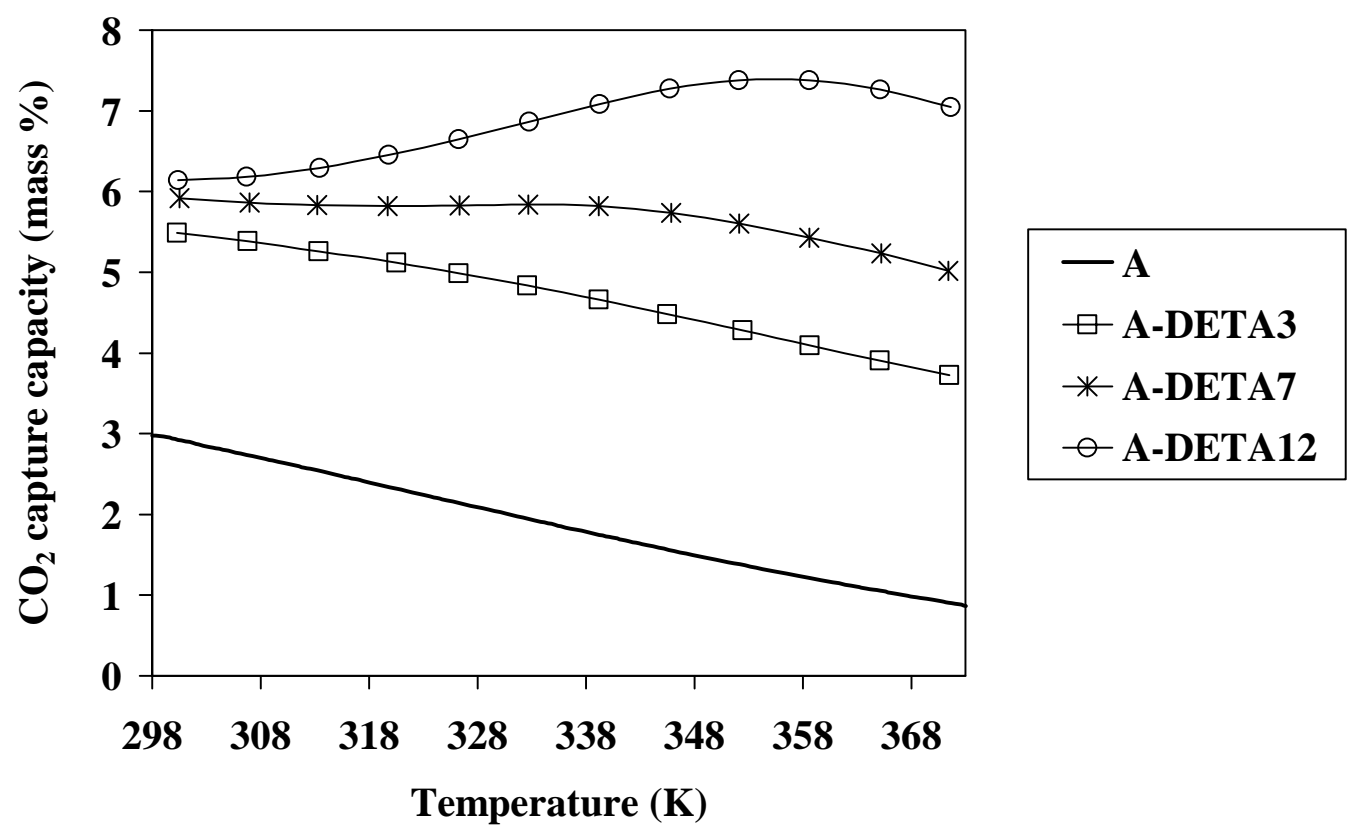

